\title{
VI. Brünings Entlassung, die Übergangskabinette Papen/Schleicher und das Ende der Reparationen
}

Die Entwicklung der inneren Verhältnisse Deutschlands hat die jetzt endlich erreichte britisch-französische Verständigung noch stabilisiert, und zwar aus einem etwas paradox anmutenden Grund. Daß die radikalen politischen Bewegungen im Reich unentwegt an Stärke gewonnen und inzwischen die im Herbst 1931 erreichte Marke bereits weit hinter sich gelassen hatten, ist in den Ländern außerhalb Deutschlands, wo Regierungen und Öffentlichkeit durch Diplomaten und Journalisten laufend über die deutsche Radikalisierung informiert wurden, mit ungläubiger Bestürzung verfolgt worden. Dabei galt die Besorgnis nicht den Kommunisten, da nichtdeutsche Beobachter klar erkannten, daß die von Ernst Thälmann geführte KPD nicht die kleinste Chance hatte, erfolgreich Revolution $\mathrm{zu}$ machen und ein Sowjet-Deutschland zu schaffen. Die Gefahr drohte augenscheinlich von rechts, von Adolf Hitler und der NSDAP. Nach einer stürmischen Reichstagssitzung, auf der sich die nationalsozialistischen Abgeordneten besonders übel aufgeführt hatten, notierte Sir Horace Rumbold tief beunruhigt: „Wie wird Deutschland wohl fahren, wenn sein Geschick in die Hände solcher Repräsentanten gerät?" 1 Neben der eindeutig antiliberalen und antidemokratischen Stoßrichtung der NS-Bewegung wurde gerade in jenen Monaten - entgegen fünfzig Jahre später getroffenen Feststellungen - nicht zuletzt ihr rabiater und rassistischer Antisemitismus wahrgenommen. Jüdische Organisationen in England dachten sogar zeitweilig daran, Premier MacDonald zu offiziellen Protesten gegen die "Judenverfolgung in Deutschland" aufzufordern ${ }^{2}$. Nach wie vor schreckten auch die ungewöhnliche Erregbarkeit und der Hang zur Gewalttätigkeit.

Welche Außenpolitik war von diesen Leuten zu erwarten? Wenn der Chef der Heeresleitung, General v. Hammerstein, in Unterhaltungen mit britischen Diplomaten vernichtende Kritik an den Führern der NS-Bewegung übte und meinte, es sei „absurd“, den „mediokren“ Hitler mit Mussolini zu vergleichen ${ }^{3}$, so wirkte das erst recht beunruhigend. Der Duce der italienischen Faschisten bewies doch immer wieder, daß ihm wenigstens ein be-

1 Rumbold an Simon, 1. 3. 1932; DBFP, Second Series, Vol. III, Nr. 95.

2 P. Scheffer, Londoner Korrespondent des Berliner Tageblatts, an Bülow, 29. 7. 1932; PA, R 29473.

3 Rumbold an Simon, 1. 3. 1932; DBFP, Second Series, Vol. III, Nr. 95. 
achtlicher Fundus an Rationalität zu Gebote stand. Angesichts derartiger Zustände war es in England ebenso wie in den USA und in Frankreich begrüßt worden, daß Feldmarschall v. Hindenburg, dessen Amtszeit ablief, sich trotz seines hohen Alters zur Wiederwahl zur Verfügung stellte. Um so heftiger fiel aber dann am 13. März der Schock aus, als Hindenburg, den die Parteien der "Weimarer Koalition“ von SPD bis DVP stützten, im ersten Wahlgang gegen Hitler, Theodor Duesterberg, den stellvertretenden Vorsitzenden des "Stahlhelm", und Thälmann die absolute Mehrheit verfehlte. Am 10. April holte er zwar 53 Prozent, doch nahm es alle Welt als Alarmzeichen, daß Hitler nicht gegen einen Sozialdemokraten, einen Mann des Zentrums oder einen Liberalen 36,8 Prozent der Stimmen gewann, sondern gegen die große Symbolfigur der preußisch-deutschen Militärtradition, ja der preußisch-deutschen Reichstradition, gegen einen Heros der Nation. Wenn selbst dieser Held, dem ein ironisches Geschick - so sah man die Dinge in London, Washington und sogar Paris - die Rolle des Hüters von Ruhe und Ordnung und des Garanten einer gewissen Berechenbarkeit der deutschen Politik zugeteilt hatte, sich fast nicht mehr gegen einen Mann zu behaupten vermochte, der aus dem Nichts kam und nichts als Umsturz, Gewalt im Innern und Gewalt nach außen verhieß, dann war die Lage in der Tat bitter ernst geworden. Hindenburg Hilfe zu bieten und seinen Kanzler möglichst lange im Sattel zu halten, erschien nun wichtiger denn je, und es lag auf der Hand, daß dabei der Konferenz von Lausanne größte Bedeutung zukam, sofern sie Brüning einen reparationspolitischen Erfolg bescherte.

Daß der Erledigung des Reparationsproblems überragende Bedeutung beigemessen wurde, aus den anerkannten wirtschaftlichen Gründen und nun auch im Hinblick auf eine dämpfende Wirkung in Deutschland, war ferner daran abzulesen, daß die Leiter der britischen und der französischen Außenpolitik auf jene kleinen Irritationen, die Deutschlands revisionistische Grundtendenz seit Jahren laufend lieferte, einige Monate lang nahezu nicht reagierten. So mißfiel es in London und vor allem Paris naturgemäß sehr, daß das Verhältnis zwischen dem Reich und der Sowjetunion trotz Moskaus Politik der Nichtangriffspakte - mit den europäischen Nachbarstaaten und selbst mit Frankreich - intim und die mit dem Schlagwort „Rapallo" ausgedrückte gemeinsame Polenfeindschaft intakt blieb. Die sowjetischen Führer erklärten den deutschen Freunden die Pakte mit dem wachsenden Druck auf Rußlands fernöstliche Grenzen, den der Expansionismus Japans schuf, und außerdem mit der Notwendigkeit, die Kollektivierung der Landwirtschaft - und andere Maßnahmen einer neuen Revolution von oben - außenpolitisch abzuschirmen ${ }^{4}$. In Berlin wurde die Begründung akzeptiert, da die sowjetischen Freunde ohne weiteres der deutschen Forde-

4 Aufzeichnung Bülow über Unterredung mit sowjetischem Botschafter, 12. 12. 1931; PA, R 29451. 
rung nachkamen, aus den Nichtangriffspakten jeden Satz herauszuhalten, der als Anerkennung irgendwelcher europäischer Grenzen und als Abkehr Moskaus vom sowjetischen - besser: russischen - Revisionismus deutbar gewesen wäre. Die Fortdauer der deutsch-sowjetischen Freundschaft ist in Paris - von Warschau ganz zu schweigen - auch deshalb übel vermerkt worden, weil die deutsch-polnischen Beziehungen gerade im Frühjahr 1932 aufs äußerste angespannt waren. Es herrschte eine Atmosphäre, in der auf deutscher Seite von polnischen Absichten gemunkelt wurde, Danzig handstreichartig zu annektieren und sogar Ostpreußen anzugreifen ${ }^{5}$, während die Marine der Reichswehr - unabhängig von den Gerüchten über polnische Pläne - den Zeitpunkt der Konferenz von Lausanne für geeignet hielt, Danzig mit mehreren Kriegsschiffen einen demonstrativen Besuch abzustatten; ein Protest der polnischen Regierung machte auf die Kriegsmarine ebenso wenig Eindruck wie die Intervention des erst gegen Ende Mai über das Vorhaben informierten Staatssekretärs v. Bülow ${ }^{6}$. Briten und Franzosen legten hingegen Zurückhaltung an den Tag.

Auch sah man es in Paris - weniger in London - gar nicht gerne, daß Italien den Zollunions-Schock so leicht überwand, die vorsichtige Annäherung an das Deutsche Reich unbeirrt fortsetzte und dabei in Berlin durchaus Gegenliebe fand; schließlich waren die französisch-italienischen Beziehungen wieder einmal auf einem Tiefpunkt angelangt, weil führende Faschisten in jenen Monaten mit leidenschaftlicher Theatralik erneut weitgehende italienische Ansprüche in Nordafrika anmeldeten ${ }^{7}$. Daß die italienisch-ungarischen wie die deutsch-ungarischen Kontakte häufiger wurden und die Skizze einer im Zeichen gemeinsamer Ablehnung des Status quo stehenden Verbindung deutlicher hervortrat, konnte ebenfalls nicht gefallen: Über Ungarn nahm Deutschlands Einfluß auf dem Balkan zu, und dies drohte, zusammen mit dem Einvernehmen zwischen Rom und Budapest, die Kleine Entente zu schwächen und ihre Funktion im französischen Bündnissystem zu erschweren.

Zugleich erwies sich die Befürchtung, Deutschland werde auf der großen Abrüstungskonferenz, die am 2. Februar in Genf mit feierlicher Rhetorik eröffnet worden war, unerbittlich die militärische Gleichberechtigung for-

5 Das begann schon 1930, so E. Freiherr v. Thermann, Generalkonsul in Danzig, an AA, 30. 9. 1930; PA, R 28321 k. Ferner Moltke an AA, 8. 6. 1932; ADAP, Serie B, Bd. XX, Nr. 121. Auch Aufzeichnung Neurath, 9. 8. 1932; PA, R 29507.

6 Aufzeichnung Bülow, 23.5.193, Aufzeichnung Völckers, Gesandtschaftsrat in der Abteilung II des AA, 23. 5. 1932, Aufzeichnung Bülow, 30. 5. 1932; PA, R 29453.

7 Außenminister Dino Grandi sagte z.B. am 4. 5. 1932 in der Kammer: „Italien könne es nicht dulden, bei der Gestaltung der neuen Entwicklung des schwarzen Erdteils übergangen zu werden und wird sich im Interesse der kommenden Generationen seinen Anteil zu sichern wissen." Ähnlich äußerte er sich zum Nahen Osten. Schubert an AA, 7.5. 1932; PA, R 29507. 
dern, als nur allzu berechtigt ${ }^{8}$. Zwar gab sich die deutsche Delegation weisungsgemäß größte Mühe, die Konferenz nicht vorzeitig in ein deutschfranzösisches Duell ausarten und dabei womöglich an erkennbarer deutscher Intransigenz scheitern zu lassen9. Auch erklärten die Vertreter des Reiches unentwegt, daß Deutschland keineswegs aufrüsten wolle - höchstens ein bißchen - und nur die Abrüstung der anderen anstrebe. Angesichts der territorialen Ziele des deutschen Revisionismus, über die Berlin ja keinen Zweifel duldete, klangen die Reden der deutschen Delegierten jedoch unaufrichtig und beschwor allein schon die deutsche Forderung auf Gleichberechtigung, die von der Sowjetunion, von Italien und von Ungarn unterstützt wurde, die düstere Vision der deutschen Aufrüstung und eines dann unvermeidlichen abermaligen europäischen Wettrüstens herauf - und das ausgerechnet auf einer Abrüstungskonferenz. Indes sind auch all diese minderen Reizungen oder erst in der Zukunft liegenden Gefährdungen vorerst recht milde behandelt worden.

Auf der anderen Seite mehrten sich Anzeichen, die auf ein positives Ergebnis der anstehenden Reparationskonferenz wiesen. Auch zeichneten sich die Umrisse einer möglichen Lösung ab. Bereits im Januar hatte Carl Bergmann, Staatssekretär a.D. und Mitglied des Verwaltungsrats der Deutschen Reichsbahngesellschaft, Brüning aufgesucht. Bergmann, der früher an der deutschen Reparationspolitik hervorragenden Anteil gehabt hatte und noch immer über exzellente Verbindungen in allen Gläubigerstaaten verfügte, kam gerade aus Paris und setzte dem Kanzler auseinander, daß die Konferenz von Lausanne selbstverständlich das Ende der Reparationen, das heißt das Ende jährlicher Zahlungen, bringen müsse. Jedoch sei eine simple „Streichung der Reparationen ohne einen irgendwie gearteten geldlichen Abschluß augenblicklich bei unseren Gegnern noch völlig unerreichbar". Dennoch dürfe nicht länger gewartet werden, da sicher sei, „daß - etwas zynisch gesprochen - die Weltwirtschaftskrise uns nicht den Gefallen tun werde, noch so lange auf ihrem Tiefpunkt zu verharren, bis [der] völlige Umschwung in der reparationspolitischen Auffassung unserer Gegner eingetreten sei“. Bergmann sagte, „daß er unter völliger Streichung der Reparationen an eine Hingabe von Anleihetitres über 4 Milliarden Gold an die BIZ in Basel“ denke. Diese titres seien „keine Anleihe, sind also noch in keiner Weise zu verzinsen und zu amortisieren. Die BIZ, die ja nach ihrem Statut für solche Dinge berufen ist, soll berechtigt sein, Teile von diesen 4 Milliarden in zweckmäßig erscheinender Stückelung auf Anleihe international auf-

8 Hierzu St. Nadolny, Abrüstungsdiplomatie 1932/33. Deutschland auf der Genfer Konferenz im Übergang von Weimar zu Hitler, München 1978.

9 Aufzeichnung Bülow über Abrüstungsbesprechung in Genf, 26. 4. 1932, mit MacDonald, Lord Londonderry, Norman Davis, Hugh Gibson, dem Vorsitzenden der amerikanischen Delegation bei der Abrüstungskonferenz, und Bülow; AdRK, Die Kabinette Brüning, Bd. 3, Nr. 727. 
zulegen." Die Auflage der ersten Tranche - zu fünf Prozent Zinsen und einem Prozent Amortisation - könne in zwei Jahren möglich sein ${ }^{10}$. Ähnliche Gedanken erreichten Berlin aus London, New York, Washington und sogar Paris ${ }^{11}$. Brüning reagierte keineswegs negativ, und im Auswärtigen Amt begann Staatssekretär v. Bülow von sich aus über solche Möglichkeiten nachzudenken ${ }^{12}$.

Der Mai brachte schließlich noch jene günstige Wendung, auf die Berthelot im Februar Lord Tyrrell vertröstet hatte. Nach den beiden Wahlgängen vom 1. und vom 8. Mai hatte Frankreich eine Kammer, in der den linken Parteien, Radikalsozialisten, Sozialisten und kleineren Gruppen, die absolute Mehrheit zugefallen war, und es gab keinen $Z$ weifel, daß - nach dem kurzlebigen Kabinett Tardieu, das vom Februar bis zum Mai Laval abgelöst hatte - Edouard Herriot, der Führer der Radikalsozialen, die nächste Regierung bilden werde (was dann am 4. Juni geschah). Jetzt schien der Erfolg der Konferenz von Lausanne endgültig gesichert. Botschafter v. Hoesch verzeichnete einen "höchst bedeutsamen Umschwung in der französischen Politik“. Die Wähler hätten "gegen die Halsstarrigkeit der französischen Außenpolitik ... und zugunsten des Friedens, der Ruhe und der Verständigung" gestimmt. Die überwältigende Mehrheit der Franzosen schrecke vor den „Perspektiven erneuter kriegerischer Verwicklungen mit Deutschland“ zurück und lehne sich gegen den Gedanken auf, „etwa um Polens willen in einen Konflikt mit Deutschland hineingezogen“ zu werden. „Sie will in Gottes Namen auf Reparationen verzichten, um die Ruhe zu haben." Die deutsche Politik finde „also jetzt in Frankreich ein durchaus verändertes Terrain" vor, und es eröffneten sich "weitreichende Ausblicke ... wie im Jahre 1924" ungeachtet der Tatsache, daß die in der Wahl geschlagenen Minister wie Tardieu und Flandin die neuen Leute „mit grausigen Geschichten über die deutsche Gefahr" überhäuften; Tardieu etwa habe Herriot „einen deutschen Einfall in Danzig und im Korridor für die nächsten 10 Tage in Aussicht gestellt"13.

In der ersten Unterredung mit Herriot erlebte Hoesch tatsächlich einen Mann, der von der „Besorgnis“ sprach, „mit der ihn das innerlich brodelnde Deutschland für die Sicherheit Frankreichs erfülle“. Auch habe Herriot die Lektüre der eben erschienenen Memoiren Stresemanns als ein „besonders schmerzliches und peinliches Erlebnis" bezeichnet, da er, der 1924 den deutschen Ministern „mit aller Offenheit entgegengekommen“ sei, in den

10 Vermerk Pünder, 15. 1. 1932; AdRK, Die Kabinette Brüning, Bd. 3, Nr. 632.

11 Schon im Herbst 1931 hatte François-Poncet Staatssekretär v. Bülow resignierend erklärt, „daß man die französische Öffentlichkeit sehr langsam an den Gedanken gewöhnen müsse, daß der Young-Plan sich nicht realisieren lasse"; Deutschland müsse Frankreich wenigstens eine „Geste des guten Willens" bieten. Aufzeichnung Bülow, 12.11. 1931; PA, R 70507.

12 AdRK, Die Kabinette Brüning, Bd. 3, Nr. 632, Anm. 4. Aufzeichnung Bülow über Gespräch mit dem französischen Geschäftsträger Pierre Arnal, 27. 5. 1932; PA, R 29452.

13 Hoesch an AA, 31. 5. 1932; PA, R 70508. 
Memoiren lesen mußte, daß sich Stresemann "gewissermaßen gebrüstet habe", ihn, Herriot, "hereingelegt zu haben“; im übrigen sei Herriot auch deshalb verletzt, weil sich Stresemann über seine Person „verächtlich“ geäußert und ihn eine „dicke Qualle“ genannt habe. Gleichwohl aber konnte Hoesch melden, daß Herriot die Unterhaltung „mit der warmherzigen Bekundung seines guten Willens" eröffnete und daran erinnerte, er sei der „Mann, der 1924 eine Ära der Verständigungspolitik eingeleitet und das Ruhrgebiet geräumt habe"14.

In Brünings Stimmung hielten sich jedoch, obschon der Linksruck in Frankreich allenthalben so optimistisch gedeutet wurde, wie Hoesch dargetan hatte, seltsam starke Elemente von Skepsis. Wohl berichtete er am 2. Mai in einer Ministerbesprechung, es sei ihm in Genf - wo er kurz an der Abrüstungskonferenz teilgenommen hatte - gelungen, „den englischen Außenminister und Sir Frederick Leith-Ross für die deutsche Auffassung zu gewinnen, daß nur die völlige Streichung deutscher Zahlungen die Wirtschaftssituation wieder herstellen könne" 15 . Er hatte anscheinend wirklich immer noch nicht recht gesehen, wie weit offen die Türen standen, die da von ihm eingerannt worden waren. Auch konstatierte er befriedigt, daß selbst Frankreich unter dem Druck der Isolierung auf der Suche nach einer „politisch möglichen Formel“ für die Beendigung der Reparationen sei; ganz allgemein habe Deutschland „durch die Angst vor einer Zusammenbruchskrise Boden gewonnen". Aber auf der anderen Seite fühlte er offenkundig seine innenpolitische Position schwächer werden. Die NS-Bewegung drängte sich immer bedrohlicher vor den Toren zur Macht, und ihr evidentes Anschwellen mußte den Reichspräsidenten und seine Berater mehr und mehr in Versuchung führen, sich mit Hitler und der NSDP irgendwie zu arrangieren, unter Umständen auch durch Beteiligung an der Macht unter Opferung des amtierenden Reichskanzlers. Während der Botschafter in Washington, Friedrich v. Prittwitz, an Bülow schrieb, er hoffe, daß Deutschland ein solches Experiment erspart bleibe ${ }^{16}$, begann sich der Staatssekretär schon darauf einzustellen ${ }^{17}$.

Am 11. Mai sprach Brüning im Reichstag und benutzte in seiner Rede, nach fortwährenden Anpöbeleien durch nationalsozialistische Abgeordnete, die Wendung, er werde die Ruhe nicht verlieren, denn die Ruhe brauche man „besonders bei den letzten hundert Metern vor dem Ziel“. Mit dieser griffigen Formulierung, die im In- und Ausland Aufsehen erregte, appellierte der Kanzler an das Nationalgefühl der „Nazis“, ihn das Reparationsproblem noch erledigen zu lassen, weil sie dem selbst auf Grund ihrer Maßlosigkeit in Auftreten und Agitation nicht gewachsen seien, zugleich appel-

14 Hoesch an AA, 1. 6. 1932; PA, R 70509.

15 AdRK, Die Kabinette Brüning, Bd. 3, Nr. 732.

16 Prittwitz an Bülow. 12. 2. 1932; PA, R 29517.

17 Bülow an Prittwitz, 25. 1. 1932; PA, R 29517. 
lierte er aber an die Stützen seiner Macht, ihn das zu Ende bringen zu lassen, was er als die im Augenblick wichtigste und als seine ureigene Aufgabe ansah. Indes war er auch keineswegs sicher, tatsächlich hundert Meter vor dem Ziel zu sein. Am 27. Mai sagte er in einer Besprechung über die in Lausanne $\mathrm{zu}$ verfolgende Taktik, daß selbstverständlich die Forderung nach Streichung der Reparationen gestellt werden müsse: „Diese Forderung wird sich allerdings kaum sofort durchsetzen lassen, wenigstens noch nicht auf dieser Konferenz." 18

Dennoch waren die Vorzeichen für die Konferenz von Lausanne ungewöhnlich günstig, wenn die Gläubiger die Tendenz verrieten, die Reparationsfrage zumindest de facto aus der Welt zu schaffen, und beim Schuldner Deutschland die Bereitschaft entstanden und gewachsen war, für dieses faktische Ende des leidigen Kapitels eine Formel zu finden, die von der Regierung Frankreichs der französischen Öffentlichkeit und von den Regierungen aller Gläubigerstaaten den USA präsentiert werden konnte. Da geschah in Berlin etwas, das die Welt ebenso verblüffte wie beunruhigte. Zwei Wochen vor Beginn der Konferenz, am 30. Mai, wurde Reichskanzler Brüning von Hindenburg entlassen.

Der Kanzler hatte das Vertrauen des Präsidenten aus mehreren Gründen verloren ${ }^{19}$ : Weil der politische Kopf der Reichswehr, General Kurt v. Schleicher, und etliche Standesgenossen Hindenburgs das Vorhaben Brünings, hoffnungslos überschuldeten ostelbischen - vor allem ostpreußischen Großgrundbesitz $\mathrm{zu}$ enteignen und für Siedlungszwecke zu nutzen, als "Agrarbolschewismus" angeschwärzt hatten; weil die rheinisch-westfälische Schwerindustrie einen Kanzler verlangte, der mit der strikten Sparund Deflationspolitik brach; weil einige Repräsentanten des alten Preußen, die das Ohr des Präsidenten hatten, Brüning - trotz seiner militärischen Meriten und Gesinnung eben doch Katholik und Mann des Zentrums - den bevorstehenden reparationspolitischen Erfolg nicht gönnten; weil die reaktionäre Kamarilla um Hindenburg selbst jenem bescheidenen Einfluß, der in Brünings parlamentsfeindlichem Konstitutionalismus der demokratischen Linken verblieben war, ein Ende machen und die Dinge noch weiter nach rechts treiben wollte. Die Voraussetzung war von Brüning freilich selbst geschaffen worden, indem er mit der steten Zurückdrängung des Reichstags eine politische Konstellation herbeigeführt hatte, in der die Intrigen einer verschwindend kleinen Clique derart bedeutende Entscheidungen $\mathrm{zu}$ erreichen vermochten. Von dem allen abgesehen, wirkte aber nicht $\mathrm{zu}-$ letzt der Zeitpunkt des Vorgangs erschreckend. Gerade jene ausländischen Beobachter, die Deutschland wohlgesinnt waren, fanden die Verantwortungslosigkeit schwer begreiflich, die daraus sprach, daß unmittelbar vor 
der so wichtigen Reparationskonferenz der Kanzler - also mitten im Strom das Leitpferd - gewechselt wurde. Wieder einmal hätten in Deutschland, so notierte Sir Horace Rumbold, kleinliche Gesichtspunkte der inneren Politik, ja Gesichtspunkte einer Kirchturmpolitik Priorität vor dem nationalen Interesse erhalten 20 .

Den zweiten Schock versetzten Hindenburg und seine Berater Deutschland und der Welt mit der Wahl des Nachfolgers. Als am 30. und 31. Mai unter den möglichen Kandidaten da und dort auch Franz v. Papen genannt wurde, winkten alle ernsthaften Beobachter der Berliner politischen Szene verächtlich ab: ausgeschlossen! Tatsächlich hatte Franz v. Papen nicht das geringste politische, administrative oder militärische Verdienst aufzuweisen, das ihn für ein höheres staatliches Amt, geschweige denn das Amt des Reichskanzlers, qualifiziert hätte. Bis zum Ende des Weltkrieges aktiver Offizier, war Papen in seiner militärischen Karriere lediglich dadurch aufgefallen, daß ihn die Vereinigten Staaten 1915 ausgewiesen hatten, weil er, damals Militärattaché in Washington, bei Versuchen ertappt worden war, Sabotageakte in Häfen der amerikanischen Ostküste und in amerikanischen Fabriken zu organisieren. Kopfschüttelnd bemerkte Außenminister Stimson, da hätten es die Deutschen doch fertiggebracht, einen Mann zum Reichskanzler zu machen, der ohne Zögern zurückgewiesen würde, sollte er als Botschafter nach Washington kommen wollen ${ }^{21}$. Von unbestreitbarem persönlichen Charme und von ebenso unbestreitbarem Vermögen, hatte der Major a.D. nach dem Krieg Aktien des Zentrums-Organs „Germania“ erworben und bei dem Blatt die Funktion des Aufsichtsratsvorsitzenden übernommen. Das erlaubte es ihm, am äußersten rechten Rand des Zentrums als Politiker zu dilettieren und von 1921 bis 1928, dann wieder seit 1930 als Abgeordneter der Partei im preußischen Landtag zu sitzen, ohne daß irgend jemand besondere politische Talente an ihm entdeckt hätte; auch bewegte sich der geschworene Monarchist im sogenannten „Herrenklub“, wiederum ohne zu den Leitfiguren jener hochkonservativen Vereinigung zu zählen. Vermutlich war es gerade die Leichtgewichtigkeit und mithin Lenkbarkeit dieses Flaneurs in den Gassen der Politik, die Schleicher und einige andere Berater Hindenburgs dazu bewogen, ihn dem Präsidenten - der Papen sehr zugetan war - als Chef einer Regierung einzureden, die ja offensichtlich als Regierung des Übergangs fungieren, das heißt die NS-Bewegung an die Macht heranziehen und durch Machtbeteiligung zähmen und in Dienst neh-

20 Rumbold an Simon, 4. 6. 1932; DBFP, Second Series, Vol. III, Nr. 122.

21 Lindsay an Simon, 1. 6. 1932; DBFP, Second Series, Vol. III, Nr. 117. Ähnlich konsterniert wenn auch in der Wortwahl dienstlich vorsichtig - berichtete der deutsche Botschafter in Washington, der eine schwere Einbuße des deutschen Ansehens und herbe amerikanische Kritik an den "Junkern und Militaristen" in der neuen deutschen Regierung meldete. Prittwitz an AA, 4. 6. 1932, 6. 6. 1932; PA, R 80151. 
men sollte 22 . Als Sir Horace Rumbold - den Briten fiel der Abschied von Brüning wohl am schwersten - zu Bülow bemerkte, die Regierung Brüning sei in England als „Damm gegen die Nazi-Flut" sehr geschätzt worden, antwortete der Staatssekretär, die neue Regierung werde versuchen, „die Flut abzulenken oder zu kanalisieren "23, und Baron Neurath, frischgebackener Außenminister unter Papen, erklärte dem Botschafter, Reichspräsident v. Hindenburg habe ihm versichert, daß Hitler ihn, Neurath, gerne lange Zeit an der Spitze des Auswärtigen Amts sehen möchte ${ }^{24}$; ein solcher Satz kam der Mitteilung gleich, daß ein Kabinett Hitler nicht länger ausgeschlossen und daß ihm, Neurath, auch in einem Kabinett Hitler die Leitung der Außenpolitik zugedacht sei. Für ein Experiment mit den Nationalsozialisten oder jedenfalls für eine abermalige gehörige Rechtsverschiebung der politischen Gewichte schien sich Papen im übrigen auch durch eine fröhliche Forschheit zu empfehlen, die dem früheren Kavallerieoffizier - zum Schaden seiner politischen Urteilsfähigkeit - geblieben war.

So durfte Franz v. Papen ein Kabinett bilden, das als „Regierung der nationalen Konzentration" präsentiert wurde, in Wirklichkeit aber eine Regierung geradezu ridiküler Reduktion war. Von Justizminister Franz Gürtner, Wirtschaftsminister Hermann Warmbold und Arbeitsminister Hugo Schäffer abgesehen, gehörten tatsächlich alle Mitglieder des Kabinetts dem Adel an, und kein Minister durfte von sich behaupten, Mandatar einer größeren Gruppe der Bevölkerung zu sein. Zunächst waren also Reichspräsident und Reichswehr die alleinigen Stützen der Regierung, war auch noch die schon äußerst schmale Basis des zweiten Kabinetts Brüning verlassen, eine vollständige Lösung vom System Brüning vollzogen. Einer solch schwachen Regierung mußte die Suche nach einer Massenbasis ohnehin eingeboren sein, und für eine derart weit rechts orientierte Regierung kam als breitere Grundlage ohnehin nur die auf der äußersten Rechten angesiedelte NS-Bewegung in Betracht.

In der Tat bereiteten Papen und seine Minister die Annäherung an Hitler und die NSDAP sogleich vor, indem sie den Reichstag auflösten und den Nationalsozialisten damit den ersehnten Wahlkampf schenkten. Mitte Juni verfügten sie außerdem die Wiederzulassung der Bürgerkriegsarmee Hitlers, der SA, und erlaubten deren Uniformierung; Brünings Innenminister Wilhelm Groener hatte Ende 1931 SA und Uniformierung verboten. Auch leiteten sie - abermals in scharfem Kontrast zur Politik Brünings - die definitive Ausschaltung der Linken, gerade auch der demokratischen Linken, aus dem politischen Leben Deutschlands ein. So veranlaßte Papen die mehr oder weniger gewaltsame Absetzung der sozialdemokratischen Minder-

22 Mommsen, Die verspielte Freiheit, S. $434 \mathrm{ff}$.

23 Rumbold an Simon, 7. 6. 1932; DBFP, Second Series, Vol. III, Nr. 127.

24 Rumbold an Simon, 3. 6. 1932; DBFP, Second Series, Vol. III, Nr. 120. 
heitsregierung in Preußen - der sogenannte „Preußenschlag“ vom 20. Juli $1932^{25}$-, und das anschließende rigorose Vorgehen gegen zahlreiche sozialdemokratisch orientierte staatliche Angestellte und auch schon Beamte kann durchaus als Vorspiel zu den „Säuberungen“ des Jahres 1933 gesehen werden.

Noch schroffer war die Abwendung von den Vorgängern auf dem Felde der internationalen Politik. Zwar suchte Neurath, zu Abschiedsbesuchen noch einmal nach London zurückgekehrt, den britischen Außenminister davon zu überzeugen, daß die deutsche Außenpolitik unter dem Reichskanzler Papen und dem Außenminister Neurath keine Änderung erfahren werde ${ }^{26}$. In Wahrheit sollte es mitnichten Kontinuität geben. Etliche Kabinettsmitglieder waren Anhänger einer wirtschaftlichen Autarkie des Deutschen Reiches ${ }^{27}$, und da Autarkie allenfalls dann machbar sein konnte, wenn ganz Mitteleuropa, große Teile Osteuropas und Südosteuropas unter deutsche Verfügungsgewalt gerieten, hatten derartige Pläne nichts mehr gemein mit bloßer Revisionspolitik, ja nicht einmal, da sie statt deutscher Hegemonie deutsche Herrschaft implizierten, mit den Visionen der Ausdehnung deutscher Wirtschaftsmacht, wie sie bei der Konzipierung der deutschösterreichischen Zollunion aufgetaucht waren.

Papen selbst war zu einem radikalen Bruch mit der bisher verfolgten Politik entschlossen: Nicht länger Feindschaft mit Frankreich und nicht länger Freundschaft mit der Sowjetunion, statt dessen deutsch-französisches Militärbündnis und dann, zusammen mit einem um die von Deutschland beanspruchten Gebiete erleichterten Polen, große gemeinsame Unternehmen gegen das bolschewistische Rußland. Für solche Ideen, deren Verwandtschaft mit der Zielsetzung Hitlers - ersetzt man das für den Nationalsozialisten wenig interessante Frankreich durch England - unverkennbar ist, hatte $\mathrm{Pa}$ pen in Vorträgen zu werben begonnen ${ }^{28}$, und am Vorabend der Konferenz von Lausanne machte im „Herrenklub“ das Gerücht die Runde, „Fränzchen" wolle bereits diese Gelegenheit benutzen, um Herriot eine politische und militärische Allianz anzubieten ${ }^{29}$.

Als Papen das am 29. Juni tatsächlich tat ${ }^{30}$, spielte er damit freilich nur dem französischen Ministerpräsidenten eine freudig ergriffene Chance zu. Herriot informierte umgehend MacDonald und Sir John Simon, die er dann mit dunklen Andeutungen über finstere Absichten, die ihm der Reichskanz-

25 Benz, Papens „Preußenschlag“.

26 Simon an Newton, 6. 6. 1932; DBFP, Second Series, Vol. III, Nr. 124.

27 Z. B. Ernährungsminister und Ostkommissar Magnus Freiherr v. Braun; vgl. v. Braun, Von Ostpreußen bis Texas, S. $201 \mathrm{ff}, 208 \mathrm{ff}$. Teichert, Autarkie.

28 Aufzeichnung Völckers, 23. 6. 1932; PA, R 28307.

29 Ebenda.

30 Aufzeichnung Papen, 29. 6. 1932; ADAP, Serie B, Bd. XX, Nr. 174. 
ler vertraulich kundgetan habe, mißtrauisch zu stimmen suchte ${ }^{31}$. Deutlicher wurde Herriot, als er auch Moskau unterrichtete, so deutlich, daß seine Mitteilung einer - durchaus Wirkung zeigenden - Warnung der sowjetischen Regierung vor den neuen Leuten in Berlin gleichkam ${ }^{32}$. Im übrigen nahmen die Franzosen Papens Offerte nicht recht ernst; angesichts der Umstände sahen sie darin begreiflicherweise lediglich ein konferenztaktisches Manöver, mit dem die Deutschen Frankreich zum Verzicht auf weitere Reparationszahlungen des Reiches und gleich auch noch zur Anerkennung der militärischen Gleichberechtigung Deutschlands verlocken wollten. Jedoch stand hinter Papens Eröffnungen in der Tat eine ernstgemeinte Konzeption. In Berlin fand ein Kurswechsel statt, und wenn Staatssekretär v. Bülow in Gesprächen protestierte, er persönlich sei keineswegs ein Anhänger der Autarkie $^{33}$, wenn er sich ferner - unterstützt vom deutschen Botschafter in Moskau - größte Mühe gab, das besondere Verhältnis zwischen dem Deutschen Reich und der Sowjetunion zu erhalten, so führte das nur dazu, daß dieser konsequente Verfechter reiner Revisionspolitik, obwohl er nach wie vor an der Spitze des Auswärtigen Amtes stand, ständig an Einfluß verlor.

Bei der nächsten Aufgabe praktischer Politik, nämlich dem Kampf gegen die Reparationen auf der Konferenz von Lausanne, sollte allerdings an Ziele und Methoden der Regierung Brüning angeknüpft werden ${ }^{34}$. Das konnte nach Lage der Dinge nicht anders sein. Die Abhalfterung Brünings hatte die deutschen Aussichten freilich verschlechtert. Zwar dachte die britische Regierung nicht daran, die Berliner Vorgänge zum Anlaß zu nehmen, ihre Haltung in der Reparationsfrage zu ändern; dazu saß die Überzeugung von der wirtschaftlichen Schädlichkeit der Reparationen mittlerweile viel zu fest. So gab Simon am 6. Juni Lord Tyrrell den für die Londoner Auffassung charakteristischen Auftrag, Herriot zu sagen, der Ministerpräsident stimme doch sicherlich mit ihm, Simon, darin überein, „daß es unter den gegebenen Umständen völlig unmöglich sein wird, Deutschland dazu zu bewegen, irgendeine Verpflichtung zu unterschreiben, jetzt oder in Zukunft Zahlungen zu leisten“. Er fügte die Mahnung an, Herriot sei gewiß mit ihm der Meinung, „daß uns ein bloßes Moratorium nicht befähigen würde, den tatsächlichen Schwierigkeiten zu begegnen, die mit dem Transfer enormer Summen, hauptverantwortlich für die Nöte der Welt, verbunden sind “35. Jedoch betrachtete der britische Außenminister die neue deutsche Regierung, der persönlichen Wertschätzung Neuraths ungeachtet, ohne jedes Vertrauen

31 Great Britain and France: Notes of a Conversation held on Tuesday, July 5; DBFP, Second Series, Vol. III, Nr. 175.

32 Dirksen an AA, 28. 2. 1933; PA, R 28307 k.

33 Aufzeichnung Bülow über Unterredung mit dem rumänischen Gesandten, 18. 8. 1932; PA, R 29453.

34 AdRK, Das Kabinett von Papen, Bd. 1, Nr. 4.

35 Simon an Lord Tyrrell, 6. 6. 1932; DBFP, Second Series, Vol. III, Nr. 126. 
und glaubte daher guten Grund zu haben, ihr das von ihm selbst so dringend gewünschte Ende der Reparationen nur gegen das Versprechen politischen Wohlverhaltens zuzugestehen. Schon bei Neuraths Abschiedsbesuch unternahm Simon den Versuch, dem nunmehrigen deutschen Außenminister klarzumachen, daß Deutschland, wenn es in der Reparationsfrage die Dienste Großbritanniens als „ehrlicher Makler" haben wolle, nicht immer bloß Forderungen nennen dürfe, sondern eine Gegenleistung erbringen müsse: die Zustimmung zu einem zeitlich befristeten „politischen Waffenstillstand"36. Und am 9. Juni ließ er nach Berlin bereits den Entwurf einer internationalen Vereinbarung eines solchen Waffenstillstands übermitteln, nicht ohne darauf hinzuweisen, daß ohne positive Berliner Reaktion der französische Widerstand gegen eine Lösung des Reparationsproblems im deutschen Sinne noch härter sein werde als ohnehin zu erwarten ${ }^{37}$.

In der Tat fielen die französischen Reaktionen heftig aus. Daß ein „Kabinett der Barone“, wie es nun in Berlin amtierte, bei einer links orientierten Pariser Regierung, nahezu gleichzeitig gebildet, auf Abneigung stoßen mußte, lag auf der Hand, und die Abneigung war naturgemäß mit stärkstem Mißtrauen verschwistert. Bei den an sich skeptischen und erst recht jeden Politiker aus Deutschland mit Argwohn aufnehmenden Franzosen hatte Brüning nie soviel Vertrauen genossen wie bei Briten und Amerikanern, doch war in den gut zwei Jahren seiner Kanzlerschaft Respekt gewachsen und in den wenigen Begegnungen mit französischen Politikern zu einigen, vor allem zu Laval, sogar ein recht gutes persönliches Verhältnis entstanden ${ }^{38}$. Auch kannte man in Paris Brünings Bereitschaft, für die Liquidierung der Reparationen eine Form finden zu helfen, die der französischen Regierung einen größeren Ansehensverlust im eigenen Lande nach Möglichkeit ersparte. Diese in der Person Brünings liegenden Vorteile hatten die Berliner Intriganten der deutschen Politik leichtfertig aus der Hand genommen. Die neuen Leute in Berlin galten Herriot und seinen Ministern einfach als Repräsentanten Preußens und des wilhelminischen Deutschland; die ohnehin nicht schlafende Erinnerung an 1870/71 und an den Weltkrieg wurde wieder hellwach.

Welch tiefes Mißtrauen den jetzt im Deutschen Reich regierenden "Junkern“ und „Militaristen“ entgegenschlug, zeigte sehr deutlich das plötzliche Nachlassen des französischen Interesses an einem „politischen Moratorium", wie es gerade eben wieder von London propagiert wurde. Nicht daß die Idee aufgegeben worden wäre, aber der richtige Eifer fehlte. In Anbetracht des grundsätzlichen Mangels an Achtung vor Verträgen, wie er nach

36 Simon an Newton, 6. 6. 1932; DBFP, Second Series, Vol. III, Nr. 124.

37 Simon an Neurath, 9. 6. 1932; DBFP, Second Series, Vol. III, Nr. 128.

38 Rumbold an Simon, 27. 1. 1932; DBFP, Second Series, Vol. III, Nr. 67. Nach Rumbold hatte François-Poncet berichtet, ihm gegenüber habe Laval den deutschen Reichskanzler als „un homme d'or" charakterisiert. 
Pariser Meinung für wilhelminische Außenpolitik charakteristisch war, konnte die deutsche Unterschrift unter einen politischen Waffenstillstand, die man von einem Kanzler Brüning noch begehrt hatte, jetzt keinen sonderlichen Wert mehr haben. Daß ausgerechnet in jenen Tagen unter dem Titel „Vermächtnis“ Aufzeichnungen und Briefe Stresemanns erschienen, die, von seinem ehemaligen Privatsekretär Henry Bernhard herausgegeben, zumindest für die ersten Jahre der Amtszeit des verstorbenen Außenministers ein ungewöhnliches Maß an Unaufrichtigkeit - namentlich gegenüber Frankreich - belegten, hat den Urteilen und Vorurteilen - von der persönlichen Kränkung Herriots ganz abgesehen - kräftige Nahrung gegeben. Kein Wunder also, daß unter den veränderten Umständen die Neigung wieder zunahm, Deutschland so lange wie nur irgend möglich in Reparationsfesseln zu halten.

In den ersten Tagen der Lausanner Konferenz trat tatsächlich eine französische Delegation auf, mit der eine definitive Verständigung in der Reparationsfrage so unmöglich schien wie ein Jahr zuvor. Neben den einladenden Staaten - Großbritannien, Frankreich, Belgien, Italien, Deutschland und Japan - hatte auch die stattliche Reihe der übrigen Gläubigerländer Vertreter geschickt: Kanada, Australien, Neuseeland, Südafrika, Indien, Griechenland, Polen, Portugal, Rumänien, Tschechoslowakei. Einfluß auf den Gang der Dinge nahmen jedoch nur Briten, Franzosen, Italiener und Deutsche. Ministerpräsident Herriot ließ nun anfänglich keinen Zweifel daran, daß eine völlige Preisgabe des Young-Plans und die Streichung der Reparationen für Frankreich nicht in Frage komme. Er zeigte sich im Plenum der Konferenz ebenso intransigent wie in den ersten bilateralen Gesprächen mit den deutschen Delegierten: Der Gedanke an Streichung der Reparationen, so sagten Herriot und Hérault Germain-Martin, sein Finanzminister, zu Papen und dem neuen Leiter des Reichsfinanzministeriums, dem Grafen Lutz Schwerin-Krosigk, sei „Zeitverschwendung“, habe „etwas durchaus Kindisches" 39 . Da andererseits die Deutschen mit der nicht weiter überraschenden Erklärung begannen, sie könnten weder jetzt noch in Zukunft eine Mark zahlen ${ }^{40}$, öffnete sich eine Kluft, über die es anscheinend keine Brücke gab. Die Briten, die sich ja schon vor der Konferenz als „ehrliche Makler“ angeboten hatten, standen offenbar vor einer kaum lösbaren Aufgabe. Es sollte auch eine saure Arbeit werden, und neben der französischen Defensivtaktik hatte daran die Persönlichkeit des Nachfolgers von Brüning keinen geringen Anteil.

39 Aufzeichnung über cine deutsch-französische Besprechung in Lausanne, 24. 6. 1932, o. N.; AdRK, Das Kabinett von Papen, Bd. 1, Nr. 39.

40 In der zweiten Plenarsitzung der Konferenz von Lausanne sagte Papen: „Die Reparationsleistungen haben sich als unmöglich und schädlich erwiesen. Die Erfahrungen schließen die Möglichkeit aus, in der Hoffnung auf künftige Entwicklungen cin neues Experiment mit den Reparationen zu machen." AdRK, Das Kabinett von Papen, Bd. 1, Nr. 30. 
Zunächst nahmen sich MacDonald, Simon und Handelsminister Walter Runciman die Begründung vor, die Herriot und Germain-Martin für die französische Haltung ins Treffen führten. Mit dem ersten Argument, nämlich daß am Young-Plan festgehalten werden müsse, weil sonst das Prinzip der Heiligkeit von Verträgen ins Mark getroffen werde, hielten sich die Briten freilich nicht lange auf; schließlich konnte niemand im Ernst behaupten, jener hehre Grundsatz werde verletzt, wenn ein Vertrag mit Zustimmung aller Vertragsparteien revidiert oder aufgehoben wird. Ernsthafter war das zweite Argument: Werde Deutschland von jeder Reparationslast befreit, genieße es - als ein Staat mit einer im Vergleich zu anderen Industrieländern sehr geringen inneren Schuld - im internationalen Handel unfaire Wettbewerbsvorteile; auch Brüning hatte die Leiden, die seine rigide Sparpolitik mit sich brachte, gelegentlich mit der Verheißung einer nach Abschüttelung der Reparationen möglichen „Exportoffensive“ zu rechtfertigen gesucht. Aber abgesehen davon, daß gegen das französische Argument zahlreiche wirtschaftliche Einwände zu Gebote standen, war es einfach schon mit dem Hinweis auf die im Augenblick vorrangige Heilbedürftigkeit der herrschenden Krise außer Kraft zu setzen. Am stichhaltigsten war das dritte und nicht zum ersten Mal vorgebrachte Argument: Die Streichung der Reparationen sei unmöglich, solange man nicht mit Washington die Streichung der alliierten Kriegsschulden vereinbart habe. Das Verlangen nach Vorsicht klang um so plausibler, als die amerikanische Administration - nur noch Monate von den Präsidentschaftswahlen entfernt - sich zweideutiger denn je vernehmen ließ ${ }^{41}$ : Einerseits keine vollständige Liquidierung der Reparationen - andererseits kein bloßes Moratorium; einerseits kein Verzicht auf das Einfordern der alliierten Kriegsschulden, was immer die Europäer über die Reparationen beschließen mögen - andererseits Nachziehen der USA, falls die Europäer das Reparationsproblem erledigen. Das lieferte der französischen Skepsis ebenso gute Gründe wie dem britischen Optimismus.

Die britisch-französischen Unterredungen waren so lang und so ermüdend, daß es die Briten nicht dabei beließen, die Argumentation der französischen Kollegen zu widerlegen, sondern auch, wie schon vor einigen Monaten, zu der Drohung griffen, die Intransigenz Frankreichs werde Großbritannien in eine Einheitsfront mit Deutschland zwingen ${ }^{42}$. Nach etlichen Tagen des Widerstreits von Thesen, Behauptungen, Klagen und Vorwürfen lichtete sich der Pulverdampf über der Walstatt. Herriot und Germain-Martin mußten einsehen, was sie im Grunde bereits vor der Konferenz gewußt hatten: Der Young-Plan und Reparationen in Form von Annuitäten konnten nicht länger verteidigt werden. Auf der anderen Seite hatten MacDo-

41 Lindsay an Simon, 1. 6. 1932; DBFP, Second Series, Vol. III, Nr. 117.

42 Great Britain and France: Notes of a Conversation, June 20; DBFP, Second Series, Vol. III, Nr. 140. 
nald, Simon, Runciman und Schatzkanzler Neville Chamberlain zu begreifen, daß die französische Delegation, um die öffentliche Meinung in Frankreich $\mathrm{zu}$ beschwichtigen, nicht ohne irgendeine deutsche Konzession nach Hause kommen durfte. Der Zwang zum Kompromiß führte schließlich zur „Entdeckung“ jener Lösung, die von Bergmann und vielen anderen Fachleuten bereits lange vor der Konferenz gefunden, erörtert und den Regierungen nahegebracht worden war: Eine Abschlußzahlung Deutschlands, die nicht offiziell in die Rubrik "Reparationen“ placiert zu werden brauchte; in Gestalt von Schuldverschreibungen bei der Bank für Internationalen Zahlungsausgleich hinterlegt - die Obligationen von der BIZ erst nach einigen Jahren auf den Markt zu bringen - und auch dann nur, wenn die deutschen und die globalen Wirtschafts- und Währungsverhältnisse nicht gestört werden. Mit anderen Worten: Die Zahl auf dem Scheck, den Deutschland ausstellen sollte, hatte eindrucksvoll zu sein, doch der Tag der Einlösung des Schecks war der Sankt-Nimmerleins-Tag ${ }^{43}$. Daß die Vertreter des Deutschen Reiches diese ingeniöse Regelung zurückweisen könnten, die allen das Gesicht wahrte, den Schlußpunkt hinter das Kapitel der Reparationen setzte und Deutschland jeder realen Zahlung enthob, schien ausgeschlossen.

Genau das aber tat Papen. Simons „politischen Waffenstillstand“ hatte Neurath schon vor Konferenzbeginn abgelehnt ${ }^{44}$. Jetzt, in seiner Rede während der ersten Plenarsitzung der Konferenz, legte Papen in wohlgesetzten Worten dar, daß er gar nicht daran denke, die deutsche Unterschrift unter dem Young-Plan in Frage zu stellen, daß jedoch die Reparationen als der Krebsschaden der Weltwirtschaft verschwinden müßten, Deutschland ohnehin nichts mehr zahlen könne und die Konferenz sich nun Plänen zur wirtschaftlichen Kräftigung Deutschlands, Europas und der Welt zuwenden solle ${ }^{45}$. Kein Zweifel, Papen glaubte damit auf Brünings Kurs zu bleiben, in Wirklichkeit war er, jedenfalls zunächst, nun auch noch in der Reparationsfrage von seinem Vorgänger abgewichen, der zuletzt doch deutlich Neigung zum Kompromiß verraten hatte. Vielleicht fühlte der Kanzler sich durch die freundliche Geste ermuntert, die Briten, Franzosen und die übrigen Gläubiger - auf britische Anregung - zu Beginn der Konferenz gemacht hatten, als sie erklärten, daß alle etwa fälligen Zahlungen gestundet seien, solange man in Lausanne konferiere ${ }^{46}$. In einer Unterhaltung mit Herriot und seinen Beratern bemerkte Neville Chamberlain ohne jede Ironie, die Konferenz stehe unter der Notwendigkeit, die Deutschen zur Annahme eines Arrangements

43 DBFP, Second Series, Vol. III, Nr. 137-163.

44 Rumbold an Simon, 11. 6. 1932; DBFP, Vol. III, Nr. 132.

45 AdRK, Das Kabinett von Papen, Bd. 1, Nr. 30. Stenographic Notes of the Second Plenary Session of the Conference, June 17, 1932; DBFP, Second Series, Vol. III, Nr. 138.

46 Ebenda. 
zu bewegen, das den deutschen Kredit wiederherstelle ${ }^{47}$; die Position der Stärke, die Deutschland auf Grund seiner Schwäche gewonnen hatte, war damit genau charakterisiert. Ein solches Arrangement wurde Papen jetzt offeriert, und er weigerte sich, während an seiner Seite Neurath ab und an Konziliantes murmelte, das Geschenk anzunehmen ${ }^{48}$.

Geduldig setzten ihm MacDonald, Simon, Chamberlain und Runciman wieder und wieder auseinander, daß die von ihnen vorgeschlagene Regelung die beiden entscheidenden Bedingungen für deutsch-französisches Einvernehmen erfülle: Sie vermittle der öffentlichen Meinung in Frankreich den Eindruck, daß Deutschland, wenn es sich wirtschaftlich wieder erholt habe, noch einmal tief in die Tasche greifen müsse, und sie gebe den Deutschen die Gewißheit, daß sie nie mehr etwas zu zahlen hätten. Da Papen darauf mit der stereotypen Klage antwortete, er könne dem armen deutschen Volk keine neuen Lasten aufbürden, kam es allerdings auch vor, daß MacDonald, ein Mann, der normalerweise mit den Repräsentanten anderer Staaten höflich umging, die Geduld verlor und Papen fragte, ob er das, was ihm gesagt worden sei, denn auch verstanden habe ${ }^{49}$. Im übrigen verursachte die reine Negation, in der Papen anfänglich verharrte, auch ebenso unsinnige wie zeitraubende deutsch-französische Rededuelle, im Plenum und in bilateralen Gesprächen. So mußte Graf Schwerin-Krosigk, vor kurzem noch Ministerialdirektor im Reichsfinanzministerium und seit Anfang Juni Mitglied des Kabinetts, in langen Ausführungen darlegen, wie groß das Elend in Deutschland sei $^{50}$, worauf Kollege Germain-Martin und Herriot nicht weniger lange Jeremiaden anstimmten, die beweisen sollten, daß es den Franzosen mindestens so schlecht gehe wie den Deutschen ${ }^{51}$. Bald drohte das Scheitern der Konferenz.

Da machte Papen plötzlich eine Kehrtwendung und bot eine Abschlußzahlung von zwei Milliarden Reichsmark an - wobei man ihn so verstehen mußte, als meine er nicht fiktive Milliarden im Bergmannschen Sinne, sondern reales Geld -, sofern die Gläubigerstaaten einige politische Bedingungen des Deutschen Reiches erfüllten: So müßten sie jenen Teil des Vertrags von Versailles offiziell außer Kraft setzen, in dem die deutsche Kriegsschuld behauptet sei, und die militärische Gleichberechtigung Deutschlands anerkennen ${ }^{52}$. Papen handelte dabei gegen den Rat Neuraths und Bülows, je-

47 Great Britain and France: Notes of a Conversation, July 2, 1932; DBFP, Second Series, Vol. III, Nr. 163.

48 Great Britain and Germany, June 20, Great Britain and Germany, June 25, Great Britain and Germany, June 27, Notes of Conversations; DBFP, Second Series, Vol. III, Nr. 141, 147, 149; AdRK, Das Kabinett von Papen, Bd. 1, Nr. 40, 46.

49 DBFP, Second Series, Vol. III, Nr. 182.

50 AdRK, Das Kabinett von Papen, Bd. 1, Nr. 39 mit Anm. 1.

51 Ebenda.

52 Great Britain and Germany, Notes of a Conversation, 3. 7. 1932; DBFP, Second Series, Vol. III, Nr. 166. AdRK, Das Kabinett Brüning, Bd. 1, Nr. 47 mit Anm. 1. 
doch mit Unterstützung etlicher der in Berlin gebliebenen Minister: Jedenfalls war es, gemessen an Papens Zielen, ein Narrenstreich. Wie er auf die Idee kommen konnte, daß Frankreich bereit sein werde, den Verzicht auf deutsche Reparationen gleich auch noch mit der Anerkennung einer zumindest partiellen französischen Kriegsschuld zu verbinden - darauf wäre die Entlastung Deutschlands ja hinausgelaufen -, ist rätselhaft. In der Tat verweigerte Herriot jede Verhandlung53. Und was die militärische Gleichberechtigung betraf, so beriefen sich Briten und Franzosen mit Recht darauf, daß die Konferenz von Lausanne zur Lösung des Reparationsproblems einberufen worden sei, und verwiesen dann kühl auf die parallel in Genf tagende und für die Frage doch wohl zuständige Abrüstungskonferenz.

Hingegen hatte Papen der französischen Delegation die sofort ergriffene Gelegenheit zu der triumphierenden Feststellung geliefert, mit der Offerte von zwei Milliarden Reichsmark habe er seine bisherige Argumentation selbst als unwahr entlarvt ${ }^{54}$. Der Kanzler und andere Angehörige der deutschen Delegation trugen aber auch insofern dazu bei, Unklarheiten zu schaffen, als sie einmal in Aussicht stellten, die zwei Milliarden in einigen Jahren komplett zu zahlen, indes ein anderes Mal von - etwa 1935 beginnenden - Annuitäten sprachen ${ }^{55}$. Beides schien darauf hinzudeuten, daß die Deutschen sich mit der inzwischen sowohl britischen wie französischen Vorstellung einer fiktiven Abschlußzahlung merkwürdigerweise nach wie vor nicht anfreunden wollten.

Für die Briten war das ebenso unverständlich wie unannehmbar; schließlich ging es ihnen darum, jede weitere Belastung Deutschlands, von einer Belastung durch künftige Jahresraten ganz zu schweigen, im allgemeinen und speziell im deutschen Interesse auszuschließen; für die Franzosen waren die genannten kümmerlichen zwei Milliarden ohnehin indiskutabel, ob real oder fiktiv. Gelegentlich machte Papen, nachdem er mit den politischen Bedingungen aufgelaufen war, sogar Miene, zum Ausgangspunkt zurückzukehren: Werde Deutschland weiterhin als zweitklassige Nation behandelt, deutete er, ermuntert von Wirtschaftsminister Warmbold und Landwirtschaftsminister Magnus Freiherrn v. Braun, an, so könne es - nicht „werde“ es - nichts zahlen ${ }^{56}$. Kein Wunder, daß der auf eine harte Probe gestellte MacDonald in der Endphase der Konferenz einmal zu Papen sagte, wenn die Deutschen „sich hinsetzten und die Geschichte ihrer Angebote schrie-

53 Great Britain and France, Notes of a Conversation, July 5; DBFP, Second Series, Vol. III, Nr. 172.

54 Great Britain, France and Germany, Notes of a Conversation, June 28; DBFP, Second Series, Vol. III, Nr. 151.

55 Great Britain and Germany, Notes of a Conversation, July 3, 1932; DBFP, Second Series, Vol. III, Nr. 168. AdRK, Das Kabinett von Papen, Bd. 1, Nr. 56.

56 Great Britain, France and Germany, Notes of a Conversation, July 6; DBFP, Second Series, Vol. III, Nr. 179. AdRK, Das Kabinett Brüning, Ministerbesprechung, 7. 7. 1932, Nr. 52. 
ben, ... würden sie es gar nicht gerne sehen, sollte die Geschichte veröffentlicht werden" 57 .

Konferenzschlachten wie die von Lausanne gleichen in mancher ihrer Phasen der Begegnung feindlicher Heere im Gefecht: Im Lärm der Reden und im Rauch des Argumentenfeuers verlieren die Streiter und ihre Führer jede Übersicht; die Bewegungen der Heerhaufen scheinen zeitweilig ohne Richtung, und das Ende, dem der Kampf zustrebt, wird vollends unerkennbar. In Lausanne stellte sich erst nach wochenlangen und oft wirren Debatten heraus, daß Papen ganz gegen seinen Willen doch dazu beigetragen hatte, den Gang der Dinge auf ein bestimmtes Resultat hinzulenken. So unseriös in der gegebenen Situation sein Vorschlag wirken mußte, Deutschland und Frankreich sollten ein Militärbündnis schließen, so unvermeidlich es war, daß seine andere taktische Idee, die vier europäischen Großmächte Deutschland, Frankreich, England und Italien könnten einen Konsultativpakt vereinbaren, im Augenblick der gleichen Bewertung verfiel - eines stand fest: Nachdem Papen einmal zwei Milliarden Reichsmark angeboten hatte, war es der deutschen Delegation nicht mehr möglich, wieder die Haltung der ersten Konferenztage einzunehmen und im Ernst zu behaupten, Deutschland könne oder werde gar nichts zahlen; Innenminister Wilhelm Freiherr v. Gayl, der in Berlin geblieben war, hat das sofort erkannt ${ }^{58}$. Den Briten fiel nun die Aufgabe zu, eine Verständigung zu sichern, die garantierte, daß eine deutsche Restzahlung - oder welchen Namen der Vorgang auch erhalten sollte - in der erwünschen Form gezahlt wurde, nämlich gar nicht, und im übrigen ging es nur mehr um die Höhe der Summe.

In Anbetracht des Faktums, daß man sich über die Höhe einer bloß fiktiven Zahlung zu einigen hatte, nahm die Auseinandersetzung, die das Problem zwischen Frankreich und Deutschland provozierte, eine auf den ersten Blick überflüssige Länge und Schärfe an. Jedoch war gerade diese Auseinandersetzung der einzige begründete und unvermeidliche Konflikt in Lausanne. Herriot und seine Delegation wußten, daß es ihnen, nach Paris zurückgekehrt, schwer genug fallen mußte, den Franzosen eine Reparationsregelung plausibel zu machen, bei der nur sicher war, daß der französische Staatshaushalt auf Jahre hinaus nicht mit deutschem Geld rechnen durfte; wenn sie dann noch eine zu geringe deutsche Abschlußzahlung zu erklären hatten, geriet das Kabinett in Gefahr. Auf der anderen Seite standen Papen und die deutsche Delegation unter noch größerem innenpolitischen Druck. Von den Nationalsozialisten, nach einer kurzen Überraschungspause Anfang Juni, ohnehin gnadenlos angegriffen, konnte sich Papen ausmalen, welch heißen Empfang er in Berlin zu erwarten hatte, sollte er einer

57 Great Britain and Germany, Notes of a Conversation, July 7; DBFP, Second Series, Vol. III, Nr. 182.

58 AdRK, Das Kabinett von Papen, Bd. 1, Ministerbesprechung, Nr. 52. 
dem Anschein nach zu hohen Abschlußzahlung zustimmen und sich dem Vorwurf aussetzen, in einer nationalen Lebensfrage schwächliche Nachgiebigkeit gezeigt zu haben; und für den 31. Juli waren Reichstagswahlen angesetzt. Daher lagen die französischen und die deutschen Vorstellungen anfänglich weit auseinander. Dachten die Franzosen an eine deutsche Restzahlung von 8 Milliarden, 7 Milliarden, 6 Milliarden, mindestens aber 5 Milliarden, so wollten die Deutschen keinesfalls über die von Papen genannten 2 Milliarden hinausgehen ${ }^{59}$.

Einmal mehr war es Sache der Briten, als „ehrliche Makler“ zu wirken. Sie verstanden die Lage beider Parteien und waren deshalb - zumal sie in der Frage der Höhe einer deutschen Zahlung auf eigenes Desinteresse pochen konnten - imstande, den Franzosen die deutschen und den Deutschen die französischen Schwierigkeiten nahezubringen. Dennoch kostete es größte Mühe, Herriot und Germain-Martin allmählich auf 4 Milliarden herunterzuhandeln, Papen hingegen von 2 auf 2,6 Milliarden zu bringen. Dabei ging es nicht ohne britische Drohungen ab und nicht ohne Argumente, deren Spitzen in Ironie und Sarkasmus getaucht waren; abermals traf der Sarkasmus vor allem Franz v. Papen ${ }^{60}$. Allerdings ist zu seinen Gunsten zu sagen, $\mathrm{da}$ die deutsche Delegation von einem Teil des Kabinetts eher zu irrationaler Verhandlungsführung angehalten wurde, sowohl hinsichtlich der deutschen politischen Bedingungen wie hinsichtlich des Zahlungsproblems, und wenn Papen auch nicht an Weisungen aus Berlin gebunden war, so blieben Signale aus der Reichshauptstadt doch nicht ohne Wirkung, zumal Papen auf Übereinstimmung zwischen Kanzler und Kabinett Wert legte. Finanzminister Graf Schwerin-Krosigk und Wirtschaftsminister Warmbold hatten schon zum Abschluß geraten, als die Franzosen bei 5 Milliarden angelangt waren ${ }^{61}$, aber der Reichsminister für Ernährung und Landwirtschaft, Freiherr v. Braun, der dem Kreis um Hindenburg viel näher stand, setzte sich noch am 1. Juli, die Konferenz war inzwischen zwei Wochen alt, vehement dafür ein, keine Mark zu zahlen, in welcher Form auch immer, und einfach die Streichung der Reparationen zu fordern'62; Ministerialdirektor Köpke kommentierte das in einem Brief an Bülow mit der Bemerkung, Braun habe in der Kabinettssitzung "mit gewohnter Frische" argumentiert und „durch wenig Reparationskenntnis und keine Sympathie für die Wirtschaft behindert" 63 .

59 Great Britain and Germany, Notes of a Conversation, July 3; DBFP, Second Series, Vol. III, Nr. 166.

60 Auch Herriot war imstande, protokollieren zu lassen, „daß er, nachdem er den deutschen Vorschlag gehört habe, in ernste Zweifel über die Intelligenz der deutschen Repräsentanten geraten sei". Great Britain and France, Notes of a Conversation, July 5; DBFP, Second Series, Vol. III, Nr. 172.

61 AdRK, Das Kabinett von Papen, Bd. 1, Nr. 52.

${ }^{62}$ AdRK, Das Kabinett von Papen, Bd. 1, Nr. 46.

63 Köpke an Bülow, 2. 7. 1932; PA, R 29453. 
Am Ende brachte MacDonald die Franzosen und die Deutschen dazu, sich auf 3 Milliarden zu einigen. In dieser Höhe sollte das Deutsche Reich Obligationen - zu 5 Prozent Zinsen und 1 Prozent Amortisation - bei der BIZ in Basel deponieren, die diese Schuldverschreibungen nach drei Jahren auf den Markt bringen durfte, sofern es die wirtschaftliche Lage Deutschlands und der Welt erlaubte. Das Ergebnis entsprach dem Rat der Sachverständigen nach Art und nach Höhe, dem bald erreichten britisch-französischen Kompromiß zumindest im Wesen und den deutschen Interessen in jeder Hinsicht. Den entscheidenden Anteil hatten die Politik und das politische Gewicht Großbritanniens; letzteres setzte sich schließlich durch, obwohl die gewissermaßen leidtragenden Franzosen und die deutschen Gewinner mit jeweils unrealistischer Zielsetzung und taktischen Schnitzern den guten Schluß lange genug hinausgezögert hatten. Im Grunde waren aber sowohl die französische wie die deutsche Delegation mit dem Resultat durchaus zufrieden. Nach Berlin zurückgekehrt, sprach Papen im Kabinett von dem "gesamtpolitischen Vorteil“, der Deutschland zuteil geworden sei $^{64}$.

In einem Punkt waren Herriot und Germain-Martin jedoch unnachgiebig geblieben. Sie hatten es standhaft abgelehnt, die europäische Reparationsregelung völlig von der amerikanischen Haltung in der Schuldenfrage zu trennen. Um trotzdem abschließen zu können, verfielen Franzosen und Briten auf den Ausweg, die Reparationsvereinbarung von Lausanne zwar sofort zu unterzeichnen, aber erst nach Ratifizierung in Kraft treten zu lassen. Die Ratifizierung wiederum sollte erst dann stattfinden, wenn die Dinge zwischen den USA und ihren europäischen Schuldnern ins reine gebracht worden waren. Die deutsche Delegation wurde mit einer Note darüber informiert und nahm zustimmend Kenntnis ${ }^{65}$. So war freilich die ursprüngliche britische Absicht zunichte gemacht, durch die eigene Großmut die Amerikaner zu gleicher Großmut mitzureißen, und die amerikanische Administration, ob die Hoovers oder die seines Nachfolgers Franklin D. Roosevelt, wurde denn auch bockbeinig und weigerte sich, einen derart offen und ungeniert ausgedrückten Zusammenhang zwischen deutschen Reparationen und alliierten Zahlungen an die USA anzuerkennen, also zuzugeben, daß die Vereinigten Staaten jahrelang indirekt Reparationen von Deutschland erhalten hatten.

Die europäisch-amerikanischen Gespräche über das Schuldenproblem brachen zusammen. Im Hinblick auf die Stimmung im Kongreß mußte es Roosevelt vorziehen, von einem Schuldnerstaat nach dem anderen mit kleinen Restzahlungen abgespeist - so von Großbritannien - oder mit simpler Zahlungseinstellung - so von Frankreich - konfrontiert zu werden. Die po-

65 DBFP, Second Series, Vol. III, Anhang zu Nr. 186. 
litischen Beziehungen zwischen den USA und den Säumigen wurden davon aber kaum berührt. Der Befreiung Deutschlands von der Reparationslast konnte der Vorgang erst recht nichts anhaben. In Lausanne hatten die Briten den auf der „amerikanischen Bedingung“ bestehenden Franzosen etwas gereizt und den eine definitive Erledigung der Reparationsfrage fordernden Deutschen tröstend gesagt, daß selbstverständlich, wie immer sich die Vereinigten Staaten verhalten mochten, das Lausanner Ergebnis nicht mehr in Frage gestellt werden könne ${ }^{66}$. Das bestätigte sich nun, obwohl eine recht sonderbare Lage eintrat: Die USA weigerten sich, den europäischen Ländern ihre Schulden zu erlassen. Infolgedessen wurde das Abkommen von Lausanne nie ratifiziert. Da das Abkommen nicht ratifiziert wurde, trat es nie in Kraft. Indes hielten sich alle Beteiligten daran; von Deutschland wurde keine weitere Reparationszahlung mehr verlangt oder geleistet. Eine völkerrechtlich nicht existente Vereinbarung erfüllte gleichwohl ihren politischen Hauptzweck.

Auf die innenpolitische Entwicklung in Deutschland gewann der Erfolg von Lausanne allerdings keinen Einfluß. Dafür zeichnete gewiß auch die verfehlte Taktik des Reichskanzlers verantwortlich. In der Kabinettsitzung, in der Papen am 11. Juli, über seine Verhandlungsführung und das erreichte Resultat Rechenschaft ablegte, konstatierte Reichswehrminister Kurt v. Schleicher nüchtern und ohne Schonung seines Freundes Papen, es „sei ... nicht an der Feststellung vorbeizugehen, daß das Kabinett als solches durch das Lausanner Ergebnis eine schwere Niederlage erlitten habe... In den Augen der Öffentlichkeit sehe die Sache folgendermaßen aus. Die Deutsche Delegation habe gesagt, daß Deutschland nicht zahlen werde, weil es nicht zahlen könne. Nachträglich habe man sich dann doch zur Zahlung bereit erklärt, für den Fall, daß politische Bedingungen durchgesetzt würden, d.h. wenn Deutschland die Wehrfreiheit zugestanden werde und Deutschland wieder eine honorige Nation geworden sei. Das politische Ziel sei dann nicht erreicht worden. Gleichwohl sei die Delegation auf den Zahlungen sitzen geblieben." 67

In den Wochen des Wahlkampfs vor dem 31. Juli, in denen die Leidenschaften einer durch Bürgerkriegsfronten gespaltenen Nation auf den Siedepunkt stiegen und die Nationalsozialisten hofften, mit einer gewaltigen propagandistischen Anstrengung einen Wahlerfolg zu erringen, der sie an die Macht brachte, ist naturgemäß auch übersehen oder bewußt ignoriert worden, daß die sogenannte Rest- oder Abschlußzahlung fiktiver Natur war. Doch lag der innenpolitische Mißerfolg mehr noch daran, daß der Bürgerkrieg, den Nationalsozialisten und Kommunisten gegeneinander und den

66 So MacDonald und Chamberlain zu Papen, Neurath und Schwerin-Krosigk am 3. 7. 1932;

DBFP, Second Series, Vol. III, Nr. 166.

67 AdRK, Das Kabinett von Papen, Bd. 1, Nr. 56. 
beide in partieller Kooperation auch gegen die demokratische Linke, gegen alle liberaldemokratischen Kräfte im Staat, gegen den im „Zentrum“ organisierten Katholizismus und gegen die von der Regierung Papen repräsentierten reaktionären Kreise führten, den Charakter der Unversöhnlichkeit und mithin der Unempfindlichkeit gegen außenpolitische Erfolge oder Mißerfolge angenommen hatte.

Vielleicht wäre es zu einer spürbaren Wirkung auf die innere Krise in Deutschland gekommen, hätten die Deutschen schon bald nach dem reparationspolitischen Triumph von Lausanne zwei Effekte sehen können: Eine Linderung der wirtschaftlichen Nöte und eine deutliche Verbesserung der deutsch-französischen Beziehungen. Jedoch stellten sich sichtbare Zeichen wirtschaftlicher Erholung kaum ein, und diese Folgenlosigkeit, die im übrigen die Überzeugung Lügen strafte, der Wegfall deutscher Reparationen und alliierter Kriegsschulden sei ein entscheidender Faktor für die Ankurbelung der Weltwirtschaft, verhinderte jede Freude und jede aus der Freude möglicherweise erwachsende Dankbarkeit, damit jede Minderung der innenpolitischen Spannung. Und im Verhältnis zu Frankreich kam es nicht nur zu keiner Besserung, sondern ganz im Gegenteil zu einer bösen Verschlechterung. Daß die in Lausanne ausgefochtenen Streitigkeiten sowohl in Berlin wie in Paris die Stimmung eher verdunkelt hatten, war zunächst daran abzulesen, daß die Idee großzügiger französischer Wirtschaftshilfe zwar auch jetzt nicht aus den Überlegungen der Regierungen und den Unterredungen der Diplomaten verschwand, aber doch mit schwindendem Engagement diskutiert wurde; das galt für die französische Seite, und es galt für Berlin, obwohl dort von manchen die Frage aufgeworfen wurde, ob man nun, nachdem die reparationspolitische Ernte in die Scheuer eingefahren worden war, gefahrloser die Hand nach französischem Geld ausstrecken könne ${ }^{68}$.

Kurz nach Lausanne brach indes ein neuer Konflikt aus. Bis in den Sommer hinein hatte die deutsche Delegation auf der Genfer Abrüstungskonferenz das unter Brüning entstandene taktische Konzept beherzigt, als Anwalt allgemeiner Abrüstung aufzutreten und im übrigen darauf zu vertrauen, daß die mangelnde Abrüstungsbereitschaft anderer Staaten, nicht zuletzt Frankreichs, der deutschen Forderung nach militärischer Gleichberechtigung und dann nach einer vorerst noch bescheidenen Aufrüstung allmählich mehr und mehr Plausibilität verschaffen werde. In der Tat hatte

68 So die Überlegung des Industriellen Otto Wolff schon Anfang Juni, am 8.6.1932 von François-Poncet Staatssekretär v. Bülow übermittelt; PA, R 29451. Am 20.7.1932 wandte sich Gustav Krupp v. Bohlen und Halbach an das AA mit der Frage, ob Bedenken gegen die Annahme von Kreditangeboten französischer Banken - veranlaßt von der Pariser Regierung bestünden. Jetzt, nach der Erledigung der Reparationen, konnten Bülow und Köpke antworten, das Amt habe keine Bedenken, falls die Kredite nicht mit politischen Bedingungen verbunden seien. Aufzeichnung Köpke, 20. 7. 1932; PA, R 28257 k. 
sich die Konferenz - was angesichts der japanischen Gewaltakte in der Mandschurei und der inneren Zustände in Staaten wie Deutschland alles andere als verwunderlich war - alsbald in einem Gestrüpp von Mißtrauen und Bedenken verfangen, während etwa Italien, Großbritannien und die USA immer deutlicher, wenn auch noch inoffiziell, ihre Anerkennung des deutschen Anspruchs bekundeten. Allerdings leistete Frankreich gerade in dieser Frage zähesten Widerstand, doch war selbst in Paris klar, wie Ministerpräsident Herriot Ende Juli Botschafter v. Hoesch zugab, daß am Ende der Abrüstungskonferenz Deutschlands „Befreiung von den Versailler Bestimmungen" stehen werde, so wie Lausanne die Liquidierung der Reparationen gebracht habe 69 . Man war also auf gutem Wege, und im Auswärtigen Amt dominierte, ebenfalls noch im Juli, die Auffassung, daß dic deutsche Delegation die Entscheidung über die deutsche Gleichberechtigung weder „erzwingen " solle noch zu erzwingen brauche $e^{70}$.

Bald darauf trat jedoch auch bei der Behandlung des Rüstungsproblems auftrumpfende Ungeduld an die Stelle besonnener Taktik. Das lag sicherlich auch daran, daß der innere Druck auf das Kabinett Papen zunahm. Bei den Reichstagswahlen blieb die NSDAP zwar noch weit von der absoluten Mehrheit entfernt, wurde aber mit 37,3 Prozent (zuvor 18,3) und 230 Sitzen (zuvor 107) stärkste Fraktion; sie war der gewichtigste Einzelfaktor in der deutschen Innenpolitik geworden. Kein Zweifel, daß Papen und seine Regierung nun den Atem von Verfolgern im Nacken fühlten, die als gefährlich mächtige Bundesgenossen oder bereits als Ablösung drohten. Wohl wichtiger war die im Reichwehrministerium - auch ohne Bedrängung durch die Nationalsozialisten - wachsende Neigung, statt mit rationalem Kalkül mit Kraftakten Handlungsfreiheit zu gewinnen. Am 26. Juli sprach General v. Schleicher im Rundfunk und griff dabei Frankreich unter Verzicht auf jeglichen Takt scharf an; überdies kündigte er an, daß Deutschland selbständige Militärpolitik betreiben werde, sollten die anderen Mächte die deutschen Ansprüche nicht erfüllen ${ }^{71}$. Als der französische Botschafter am nächsten Tag protestierte, antwortete Außenminister Neurath kühl, die Franzosen hätten kein Recht, Reden eines Ressortministers zu kritisieren; sie seien in solchen Dingen allerdings von den bisherigen Reichsregierungen „verwöhnt" worden ${ }^{72}$.

Wie zu erwarten, reagierten Frankreich und sowohl Großbritannien wie die USA recht unwirsch; die französische Haltung versteifte sich auch in der Sache. Am 29. August überreichte Neurath, der sich abzeichnenden Isolierung des Reiches ungeachtet, dem französischen Botschafter eine Denk-

69 Hoesch an AA, 29. 7. 1932; PA, R 70509.

70 Aufzeichnung Bülow, 12. 7. 1932; PA, R 29507.

71 Schulthess', 1932, S. $128 \mathrm{ff}$.

72 Aufzeichnung Neurath, 27. 7. 1932; PA, R 70509. 
schrift der Reichsregierung, in der keine Zurückhaltung mehr gewahrt war und die Formel vom deutschen Recht „auf einen seiner nationalen Sicherheit entsprechenden Rüstungsstand" auftauchte ${ }^{73}$. Die französische Replik konnte in Berlin, wo sie am 11. September einging, nicht befriedigen ${ }^{74}$, und am folgenden Tag ließ sich Neurath vom Reichskabinett ermächtigen, der französischen Regierung und Arthur Henderson, dem Präsidenten der Abrüstungskonferenz, mitzuteilen, daß es Deutschland „ablehnen müsse, bei der weiteren Verhandlung zur Abrüstungsfrage in Genf vertreten zu sein"75.

In Erwartung der in der Tat losbrechenden weltweiten Kritik hatte Baron Neurath eine Woche zuvor an Staatssekretär v. Bülow, dem überflüssige und obendrein derart grobe Provokationen ein Greuel waren, geschrieben: „Wir müssen uns bei der Aufnahme dieses Kampfes darüber klar sein, daß uns nur die stärkeren Nerven zum Erfolg führen können."76 Der Erfolg blieb auch nicht aus. $\mathrm{Da}$ einerseits eine Abrüstungskonferenz ohne deutsche $\mathrm{Be}$ teiligung eine Farce gewesen wäre, andererseits kein Mittel zu Gebote stand, die Deutschen an den Verhandlungstisch zurückzuzwingen, mußte die deutsche Forderung schließlich erfüllt werden - wenigstens annähernd. Bis zum 11. Dezember rangen Amerikaner, Briten und Italiener den Franzosen eine Erklärung ab, in der es hieß, „daß einer der Grundsätze, die die Konferenz leiten sollen, darin bestehen muß, Deutschland und den anderen durch die Verträge abgerüsteten Staaten die Gleichberechtigung zu gewähren, in einem System, das allen Nationen Sicherheit bietet, und daß dieser Grundsatz in dem Abkommen, das die Beschlüsse der Konferenz enthält, verwirklicht werden soll" $" 77$.

Danach kehrten die Deutschen nach Genf zurück, und die Konferenz vertagte sich am 14. Dezember auf den 31. Januar 1933. Jedoch war der Erfolg Berlins um einen hohen Preis erkauft worden. Kaum war der Streit um die Reparationen zu Ende, hatte eine neue deutsch-französische Kontroverse die Regierung beschäftigt und die Öffentlichkeit aufgewühlt. Diese zusätzliche Reizung des sowieso schon hoch gereizten deutschen Nationalismus, neben der kein Gefühl für den Sieg von Lausanne aufkam, wurde ein Element bei der Verschärfung des deutschen Bürgerkriegs, und zwar ein Element, das sich naturgemäß für Deutschnationale und Nationalsozialisten günstig auswirkte. Reichskanzler v. Papen hat das nicht erkannt, und wenn er es erkannt hätte, wäre es ihm als Gewinn für die Rechte vermutlich willkommen gewesen, obwohl jegliche Kräftigung der Nationalsozialisten das

73 ADAP, Serie B, Bd. XXI, Nr. 20.

74 ADAP, Serie B, Bd. XXI, Nr. 47.

75 AdRK, Das Kabinett von Papen, Bd. 2, Nr. 132.

76 Neurath an Bülow, 6. 9. 1932; PA, R 29507.

77 Schulthess', 1932, S. $481 \mathrm{f}$. 
Eindämmungs- und Kanalisierungskonzept erschwerte und obwohl die neuerliche Herausforderung Frankreichs dem frankophilen Aspekt seiner außenpolitischen Zielsetzung glatt widersprach.

Indes war der Boykott der Genfer Abrüstungskonferenz ohnehin der letzte nennenswerte außenpolitische Akt des Kabinetts Papen. Der Kanzler und seine Regierung sahen sich in den letzten Monaten der am 3. Dezember endenden Amtszeit Papens derart von innenpolitischen Problemen und Konflikten absorbiert, daß die Außenpolitik, wie Staatssekretär v. Bülow in einem Brief etwas wehmütig bemerkte, abzudanken hatte ${ }^{78}$. Nur ein halbes Jahr hatte Franz v. Papen als Reichskanzler fungiert. Das ist normalerweise eine zu kurze Spanne, um einen Amtsinhaber und seinen Kabinettskollegen gestalterischen Einfluß auf die Politik ihres Landes zu erlauben. Im Falle der Regierung Papen verhielt es sich anders. In der Außenpolitik - wie auch in der Innenpolitik - geschah nämlich in diesen Monaten die Abkehr von allen Zielen und Methoden, die noch in Weimarer Maßstäbe paßten, und der Übergang zu jener neuen Periode, die von den Ambitionen und Formen des nationalsozialistischen Expansionismus bestimmt wurde.

Die beiden Kabinette Brüning hatten anti-französische Positionen bezogen, um, vorerst propagandistisch-rhetorisch, den Angriff auf den territorialen Status quo Kontinentaleuropas einzuleiten, sie hatten im Dienste solcher Absichten frühe Fäden einer gegen das französische Sicherheitssystem gerichteten Bündnispolitik zu knüpfen und dem speziellen deutschen Verhältnis mit der Sowjetunion größere Intimität zu geben gesucht, sie hatten mit dem Projekt der deutsch-österreichischen Zollunion sogar einen ersten konkreten Schritt zum Ausbruch aus der französisch dominierten Friedensordnung unternommen und sie hatten, überwiegend durch Verschlechterung der wirtschaftlichen „Krankheit“ Deutschlands, die Reparationsfrage forciert. Dies alles stellte einen klaren Bruch mit den Grundsätzen und den taktischen Rezepten Stresemannscher Politik dar, aber noch keinen Bruch mit sämtlichen Möglichkeiten und Elementen Weimarer Außenpolitik; im Grunde handelte es sich eher um eine Rückkehr zu den Emotionen, den Tendenzen und auch dem Verhalten, die in den Jahren 1920 bis 1924 herrschend gewesen waren. Schon solche Verschärfung und Tempobeschleunigung des deutschen Revisionismus schufen Gefahren: sie störten das ruhebedürftige Europa, sie kündigten die Verletzung vielfältiger Interessen bestimmter Staaten an und sie riefen daher immer wieder sogar Kriegspsychosen hervor. Auf der anderen Seite zeigten gewisse anglo-amerikanische und gelegentlich selbst französische Reaktionen auf die lauter und lauter angemeldeten deutschen Ansprüche, daß die konsequente Fortsetzung eines derartigen Revisionismus durch ein Deutsches Reich, das nach Rückgewinnung der finanziellen und militärpolitischen Bewegungsfreiheit über ent-

78 Bülow an Scheffer, 14. 9. 1932; PA, R 49473. 
sprechende Machtmittel verfügte, zwar sicherlich an den Rand eines europäischen Krieges geführt hätte, vermutlich jedoch nicht über den Rand hinaus.

Papen hingegen begann die deutsche Außenpolitik vom Revisionismus zu lösen. Nicht im Sinne eines Verzichts auf revisionistische Etappen. Aus praktischen wie aus propagandistischen Gründen hatte das Deutsche Reich bei jeder territorialen Machterweiterung revisionistische Phasen zu passieren; das schrieb die Geographie ebenso zwingend vor wie die Notwendigkeit, die Nation für Grenzüberschreitungen zu mobilisieren, die mit dem Risiko eines Krieges verbunden sein mußten. Doch im Zeichen einer autarkistischen Ideologie schmiedete er deutlich erkennbar - wenngleich naturgemäß erst zu Ansätzen gelangend - Pläne, die, bei Ruhigstellung Frankreichs, auf ein nicht länger begrenztes, ja überhaupt nicht mehr irgendwie definiertes Ausgreifen nach Osten und Südosten zielten. Das hatte seinem Wesen nach mit Revisionismus nichts mehr zu tun, und ein Mann wie der Staatssekretär v. Bülow, die Personifizierung revisionistischer Politik, wurde schon unter Papen und dem Außenminister v. Neurath zum Relikt einer abgelebten Periode. Das Denken Papens und etlicher Mitglieder seines Kabinetts schlug vielmehr eine Brücke zu jener „Raumpolitik“, die seit Jahr und Tag der Führer der NS-Bewegung in Büchern, Aufsätzen und Reden den Deutschen predigte. Am 29. Juli 1932, als sich der französische Ministerpräsident Herriot bei Botschafter v. Hoesch über die Rundfunkrede beklagte, die Reichswehrminister v. Schleicher am 26. Juli gehalten hatte, sprachen die beiden, denen die deutsch-französische Verständigung und der Friede in Europa so sehr am Herzen lag, noch lange über die allgemeine Situation. Am Ende, so notierte Hoesch, blieb Herriot „sorgenvoll und meinte düster, er sehe viele Dinge kommen"79.

Nun ist Franz v. Papen am 3. Dezember 1932 von eben jenem General Schleicher im Reichskanzleramt abgelöst worden, dessen Rede Herriot so besorgt gestimmt hatte. Ein französischer Regierungschef konnte denn auch keinen Anlaß sehen, von dem Berliner Wechsel eine wohltätige Wirkung auf die internationalen Beziehungen in Europa zu erwarten. Den Grund für Pariser Skepsis lieferte aber gerade nicht die Annahme, Kurt v. Schleicher werde die Politik seines Vorgängers fortsetzen, womöglich radikaler zugespitzt. Im Gegenteil. Es stellte sich ja sehr rasch heraus, daß Schleicher die politische Isolierung, in der die Regierung Papen - mit dem Reichswehrminister Schleicher - existiert hatte, als einen nicht lange erträglichen Zustand ansah ${ }^{80}$. Er unternahm Anstrengungen, seinem eigenen Kabinett eine breitere politische Basis zu schaffen, und zwar durch die Gewinnung eines von Hitler zu trennenden gemäßigten Flügels der NSDAP wie auch durch die 
Gewinnung der Gewerkschaften. Ersteres war gewiß ein Versuch am untauglichen Objekt, und der zweite Teil dieser taktischen Konzeption erwies sich ebenfalls als unanwendbar, nicht zuletzt auf Grund des Mißtrauens, das die Gewerkschaftsführer einem General entgegenbrachten, der obendrein als intrigant und unzuverlässig galt. Jedoch war die Tendenz zu erkennen, ein System zu etablieren, das mehr Ähnlichkeiten mit dem System Brünings als mit der Diktatur Papens haben sollte.

Parallel dazu durfte Schleicher die Neigung zugesprochen werden, auch in der Außenpolitik bei Brüning und nicht bei Papen anzuknüpfen. Als er am 15. Dezember 1932 sein Regierungsprogramm in einer großen Rundfunkrede darlegte, spielte die Außenpolitik verständlicherweise, angesichts der katastrophalen Wirtschaftslage, nur eine bescheidene Rolle. Immerhin fanden sich in der Rede Wendungen, die starke Anklänge an die im Herbst 1930 von Curtius geprägte Formel von der evolutionären Revisionspolitik aufwiesen ${ }^{81}$. Daß er im Lager der Revisionisten stand - zumindest angesichts der 1932 gegebenen Umstände - und nicht dem Papenschen Expansionismus anhing, ergab sich aber mehr noch aus seiner unbezweifelbaren Unterstützung der deutsch-sowjetischen Zusammenarbeit, die auf der anderen Seite antipolnische und frankophobe Ausrichtung bedeutete. Die Herren im Kreml hatten daher Papens Sturz und seine Ablösung durch Schleicher mit größter Befriedigung aufgenommen; in Moskau genoß der General als Garant des deutsch-russischen Spezialverhältnisses volles Vertrauen $^{82}$.

Um so größer war der Schock, den die sowjetischen Führer erlebten, als Schleicher aus innenpolitischen Gründen schon nach knapp zwei Monaten scheiterte. Statt seiner mutmaßlichen Intention folgen und zum außenpolitischen Kurs der Kabinette Brüning zurückkehren zu können, mußte er, noch ehe die Intention Gestalt anzunehmen vermochte, einer Regierung weichen, als deren Kanzler der Chef der NSDAP, der erklärte Expansionist Adolf Hitler, fungierte und in der als Vizekanzler der nicht minder gefährlich wirkende Papen wiederkehrte. Die Kombination Hitler/Papen wurde im Kreml als äußerst bedrohlich empfunden, zumal in der neuen Regierung Alfred Hugenberg, der Vorsitzende der Deutschnationalen, das Wirtschaftsministerium übernommen hatte, ein Mann, den Nikolaj Krestinski, der stellvertretende Volkskommissar für auswärtige Angelegenheiten, im Gespräch mit Botschafter Herbert v. Dirksen ungeniert einen doktrinären Autarkisten und folglich Expansionisten nannte ${ }^{83}$. Die sowjetische Führung reagierte umgehend. Waffenbestellungen wurden nun in Frankreich untergebracht, und es setzten sofort Bemühungen ein, den sowjetisch-französi-

82 Dirksen an Bülow, 31. 1. 1933; PA, R 29518.

83 Ebenda. 
schen Beziehungen eine Qualität zu geben, die zumindest westeuropäische Rückendeckung für außenpolitische Abenteuer des Dritten Reiches verhinderte und im weiteren Verlauf eine diplomatische Frontbildung gegen die neuen Herren Berlins ermöglichte ${ }^{84}$. Der sozusagen zweite und nun definitive Abschied von der Weimarer Republik, den die Übernahme der Macht durch das Kabinett Hitler/Papen darstellte, provozierte also, da für Osteuropa gefahrvoll und für Westeuropa noch weit weniger schmackhaft als der Revisionismus Brünings, die ersten Bewegungen zu jener außenpolitischen Isolierung, die das Dritte Reich bis 1936 gefangen halten sollte. Im Auswärtigen Amt suchte man sich zu trösten. Staatssekretär v. Bülow hatte bereits in den Monaten zuvor die Zuversicht bekundet, das Amt werde auch unter einer Regierung Hitler die deutsche Außenpolitik auf gutem Wege halten können ${ }^{85}$. Am 31. Januar 1933 schrieb ihm Dirksen einen Brief, in dem der Botschafter die sowjetischen Befürchtungen vorsichtig als wohl berechtigt bezeichnete ${ }^{86}$. Bülow antwortete beruhigend: „Ich glaube man überschätzt dort die außenpolitische Tragweite des Regierungswechsels. Die Nationalsozialisten in der Regierungsverantwortung sind natürlich andere Menschen und machen eine andere Politik als sie vorher verkündigt haben. Das ist immer so gewesen und bei allen Parteien dasselbe." 87

In den folgenden Wochen und Monaten dürfte der Staatssekretär manchmal etwas unsicher geworden sein, ob seine zynische Zuversicht der Entwicklung in Deutschland gerecht werde. Schließlich mußte er jetzt einen nicht geringen Teil seiner Zeit darauf verwenden, aufgebrachte Botschafter und Gesandte zu beschwichtigen, die gegen die brutale Mißhandlung britischer, italienischer, litauischer, französischer, belgischer und sonstiger nichtdeutscher Staatsbürger durch Schlägertrupps der SA protestierten; der Fremdenhaß, der - zumal wenn Fremde für Juden gehalten wurden - im ganzen Land losbrach, war in der Tat furchterregend und - das vor allem unheilverkündend. Gleichwohl: Nicht nur sich selbst suchten Bülow und Neurath etwas vorzumachen. So versicherte der nun tatsächlich, wie er das im Sommer des Vorjahres prophezeit hatte, auch einem Kabinett Hitler als Außenminister angehörende Baron Neurath dem britischen Botschafter, er habe sein Verbleiben im Amt von der Bedingung abhängig gemacht, „freie Hand" zu haben; daher brauche niemand zu befürchten, daß es in der $\mathrm{Au}$ ßenpolitik des Deutschen Reiches „Experimente" geben werde ${ }^{88}$. Selbst Leopold v. Hoesch, der als Nachfolger Neuraths nach London versetzt worden war, wollte dort Sir John Simon zu der Ansicht bekehren, der in-

84 Weingartner, Stalin und der Aufstieg Hitlers; Rosenfeld, Sowjetunion und Deutschland 1922-1933; Geyer (Hrsg.), Sowjetunion, S. $231 \mathrm{ff}$.

85 Bülow an Prittwitz, 25. 1. 1932; PA, R 29517.

86 Dirksen an Bülow, 31. 1. 1933; PA, R 29518.

87 Bülow an Dirksen, 6. 2. 1933; PA, R 29518.

88 Rumbold an Simon, 4. 2. 1933; DBFP, Second Series, Vol. IV, Nr. 235. 
nere Wandel in Deutschland werde keine Auswirkung auf die Außenpolitik haben. Und der britische Außenminister ließ sich sogar - bereits die Neigung Londons zur unbeirrten Fortsetzung der Appeasement-Politik verratend - auf das Spiel ein und erwiderte, es sei doch beruhigend, „daß Minister, mit denen man in Lausanne so eng zusammengearbeitet habe, weiterhin im Amt seien"89.

Den in Berlin stationierten Diplomaten, die das Geschehen in Deutschland aus nächster Nähe und ohne jeden Anlaß zur Selbsttäuschung beobachteten, konnte jedoch kein Sand in die Augen gestreut werden. Noch im Dezember hatte Sir Horace Rumbold nicht allein die allgemeine Beruhigung, die während der Kanzlerschaft des Generals v. Schleicher im ganzen Deutschen Reich eingetreten war, mit Befriedigung registriert, sondern ebenso die auch für die Außenpolitik eine Abkehr vom Kurs Papens signalisierende Bemerkung des Generals, „er könne die Idee der Autarkie, die einige Befürworter in Deutschland habe, nur verdammen" 90 . Jetzt aber, keine acht Wochen später, mußte er die Wiederkehr Franz v. Papens zur Kenntnis nehmen, und zwar Papens Wiederkehr in höchst abstoßender Gesellschaft. Mit klarerem Blick, als ihn die deutschnationalen Bundesgenossen Hitlers und mit ihnen bereits Millionen deutsche Bürger besaßen, schrieb Sir Horace schon am 7. Februar 1933, wenn Herr v. Papen glaube, „er habe die Nazi-Bewegung nun eingefangen und vor den Karren der

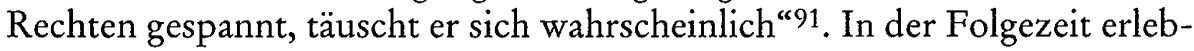
ten die Repräsentanten des Auslands, ob Diplomaten oder Korrespondenten, wie „Hitler, Papen und Hugenberg auf jede konstruktive Arbeit“ verzichteten „und ihre Energie derzeit auf die Zerstörung der bürgerlichen Freiheiten und die Beseitigung des parlamentarischen Regierungssystems“ konzentrierten ${ }^{92}$. Ohne die Charakterisierung namentlich der SA-Führer als „Gangster" zu scheuen, berichtete Sir Horace Rumbold, daß die Nationalsozialisten und ihre deutschnationalen Komplicen einerseits mit allen möglichen Tricks und Manövern, nicht zuletzt mit rücksichtsloser Gewaltanwendung, die auf den 5. März angesetzten Reichstagswahlen zu manipulieren suchten, andererseits der Nation unverblümt erklärten, daß sie, wie immer die Wahl ausfallen werde, die Macht nicht mehr aus der Hand zu geben gedächten 93 .

Und zu alledem kam, wie die ausländischen Missionen notierten, kein Wort aus dem Präsidialamt ${ }^{94}$. Der Reichspräsident, seine Umgebung und die neue Führung der Reichswehr waren offensichtlich nicht gewillt, den

89 Simon an Rumbold, 31. 1. 1933; DBFP, Second Series, Vol. IV, Nr. 232.

90 Rumbold an Simon, 21. 12. 1932; DBFP, Second Series, Vol. IV, Nr. 222.

91 Rumbold an Simon, 7. 2. 1933; DBFP, Second Series, Vol. IV, Nr. 238.

92 Rumbold an Simon, 22. 2. 1933; DBFP, Second Series, Vol. IV, Nr. 243.

93 Ebenda.

94 Ebenda. 
Nationalsozialisten in den Arm zu fallen. Im Gegenteil. Mit Verordnungen, die Hindenburgs Unterschrift trugen, obwohl sie Grundrechte suspendierten und den Repräsentanten eines großen Teils der Bevölkerung bis zum 5. März einen fairen Wahlkampf unmöglich machten, zeigte der Präsident und zeigte durch ihn die Armee, daß die Transformierung des Staates in eine Rechtsdiktatur ihre Zustimmung und Unterstützung fand. Das Erlebnis dieses Prozesses machte den Diplomaten bewußt, daß sie Zeugen eines Abschieds wurden, wenn sie bei den Akteuren in brauner Uniform „eine Verantwortungslosigkeit und eine frivole Mißachtung eines jeglichen anständigen Empfindens“ konstatierten, die in Deutschlands "Geschichte ohne Beispiel“ seien ${ }^{95}$. Deutschland verabschiedete sich gleichsam von allen Traditionen und Möglichkeiten, die bislang seine Entwicklung bestimmt hatten. Hier sah man nicht etwa einer Rückkehr zum Wilhelminismus zu, hier fand ein revolutionärer Wandel statt, der durchaus Neuem, und zwar offensichtlich Bösem und Feindlichem zur Herrschaft im Deutschen Reich verhalf. Und Deutschlands Nachbarn hatten - das lehrte das Gebaren der jetzt zwischen Rheinland und Ostpreußen mit der Macht hantierenden Rabauken und Ignoranten deutlich genug - nicht weniger Grund zur Angst vor terroristischer Politik als Deutschlands Sozialisten, Demokraten, Liberale und Christen. Es geschah weit Schlimmeres als der Bruch mit der Politik Stresemanns, der im Sommer und Herbst 1930 Europa verstört hatte. Der britische Botschafter faßte das in den Satz: „Die Vergangenheit ist ausgelöscht, und Staatsmänner wie Stresemann sind vergessen. “96

96 Rumbold an Simon, 7. 3. 1933; DBFP, Second Series, Vol. IV, Nr. 259. 